\title{
Examining food insecurity among food bank members in Greater Vancouver
}

Eleanor Holmes ${ }^{\mathrm{a}}$, MSc RD, Jennifer L. Black ${ }^{\mathrm{a}}, \mathrm{PhD}$ RD, Adeleke Fowokan ${ }^{\mathrm{b}}, \mathrm{MPH}$, Darlene Seto $^{\mathrm{c}}, \mathrm{MA}$, Scott A. Lear ${ }^{\mathrm{d}}, \mathrm{PhD}$

${ }^{a}$ Faculty of Land and Food Systems, University of British Columbia - Vancouver

${ }^{b}$ Department of Biomedical Physiology and Kinesiology, Simon Fraser University - Burnaby

${ }^{\mathrm{c}}$ Greater Vancouver Food Bank - Vancouver

${ }^{\mathrm{d}}$ Faculty of Health Sciences, Simon Fraser University - Burnaby

Corresponding author: Jennifer L. Black j.black@ubc.ca 604-822-6869

Acknowledgements: This project was funded by the Canadian Institutes of Health Research (FRN: 139544), and the McConnell Foundation. This project would not have been possible without the support of the Greater Vancouver Food Bank and the valuable input from the staff, volunteers, and members who participated in the research process. We thank research team members Joanna Mendell, Myra Cheung, Loulou Chayama, and Vera Sklyarenko for their valuable contributions to research design, data collection, and community outreach.

\begin{abstract}
Background: Few studies have described predictors of severe food insecurity among food bank users. A survey of 77 Vancouver food bank members assessed socio-demographic characteristics, food bank use and household food insecurity (HFI). Fisher's exact tests explored associations between member characteristics and severe HFI.

Results: Participants reported low incomes and $84 \%$ relied on social assistance. On average, members used food banks twice per month, $54 \%$ were long-term users ( $>5$ years) and $66 \%$ reported severe HFI. Neither frequency nor duration of food bank use were significantly associated with severe HFI. This study supports growing evidence that food bank use does not ameliorate severe HFI.
\end{abstract}

This is an Accepted Manuscript of an article published by Taylor \& Francis in Journal of Hunger and Environmental Nutrition on April 25, 2018, available online: http://www.tandfonline.com/doi/full/10.1080/19320248.2018.1465001 


\section{Introduction}

In 2012, over 1.7 million Canadian households (13\%) experienced household food insecurity (HFI), defined as limited financial access to nutritionally adequate, safe, and acceptable food $^{1}$. Charity-based approaches including food banks have been widespread in the North American response to $\mathrm{HFI}^{2}$. Food banks primarily act as food redistribution centres which collect food through charitable donations from the public, food producers, and food retailers, and distribute these items to individuals in their communities ${ }^{3}$. Food banks proliferated throughout the 1980's in North America as an emergency response to assist individuals through the economic recession ${ }^{4}$. However, what was intended as a temporary solution is now a widespread service for low income Canadians, and in 2015, Canadian food banks reported the highest number of users on record ${ }^{5}$. In British Columbia (BC), where $11.8 \%$ of households reported experiencing any food insecurity in $2012^{6}$, over 100,000 people accessed food at food banks in a single month in 2015 , representing a $28 \%$ rise since $2008^{5}$. It has been argued that the "public legitimacy" of food banks, has allowed charitable food to be framed and accepted as an appropriate solution to the problem of $\mathrm{HFI}^{2}$. However, the capacity of food bank programs to substantially reduce food insecurity has been called into question. For example, a 2012 study of families in Toronto suggested that reported food bank use was not associated with a decrease in food insecurity status a year later ${ }^{7}$. Moreover, despite growing use, little scholarly work has examined the experiences of food bank users or to what extent food bank services impact food insecurity ${ }^{8}$.

HFI is experienced across a spectrum ${ }^{1}$, with increasing severity of food insecurity being associated with declines in nutrient intakes ${ }^{9,10}$ alongside a higher prevalence of chronic and mental health issues, and health care utilisation ${ }^{11,12}$. In Canada, $2.6 \%$ of the population experiences the most severe level of $\mathrm{HFI}^{1}$. While no nationally representative studies have examined HFI and experiences amongst food bank users, estimates from studies in Toronto, British Columbia, and Hartford, Connecticut suggest that prevalence of the most severe level of 
HFI amongst food bank users have ranged from $23 \%$ to $68 \%{ }^{13-15}$. A study from the US reported that food bank users under sixty years of age had higher odds of reporting any food insecurity ${ }^{15}$, however, no studies have sought to determine if specific factors, such as sociodemographic characteristics or food bank utilisation frequency, are associated with the most severe experiences of HFI. Such insight could help identify factors which may significantly buffer or exacerbate severe HFI for this particularly vulnerable population.

The objectives of this study were therefore to work in partnership with a food bank organization: 1) to create a descriptive profile of a sample of food bank members, including their socio-demographic characteristics, length and frequency of food bank use, dietary intake, and HFI status; and 2) to explore whether member characteristics, including age, gender, household size, household structure, education, monthly income, housing costs, employment, income source, and food bank usage patterns are associated with severe HFI.

\section{Methods}

A community-based participatory research $(\mathrm{CBPR})^{16}$ approach engaged community members of a local food bank in Metro Vancouver in the research process. To promote inclusivity, when first accessing food through this organization, individuals register as food bank "members". Alongside a team of academic researchers, food bank staff and volunteers were involved in the research question development and study design. A food bank member also served as a peer research assistant, who provided feedback regarding the design and implementation of the study and supported the research team by playing a major role in community engagement, participant recruitment, and data collection.

\section{Participant recruitment}

Our food bank partner organization provides food through 13 sites and serves approximately 6500 individuals each week. This study was part of a preliminary community consultation and engagement process, which in addition to the objectives of this current study, 
aimed to broadly assess the feasibility and challenges of directly engaging members in research activities to examine the impacts of food bank services on members' experiences. As such, three food bank sites were identified by our community partner as recruitment sites for this initial survey project due to their available space, well-established relationships with the research team and the capacity of their volunteer teams to support research activities. These sites represented three distinct neighbourhoods across Metro Vancouver, and small, medium, and large site sizes in terms of the number of members served each week.

Sites were each open once per week, and recruitment was undertaken during normal operating hours between July and September 2015. As an exploratory study that aligned with our CBPR strategy, we sought to inform food bank members about our research project through posters and brochures on site, and research team personnel informed members about the study as they waited to receive food bank provisions. If members were interested, they were directed to an information booth for further information. To encourage inclusivity in the research process, food bank members were recruited via convenience sampling and were not individually selected to participate or to interrupt their food bank activities to engage in research. Eligibility criteria included age $>18$ years old, being a member of the food bank, the ability to communicate in English, and without a cognitive impairment affecting ability to provide informed consent. Participants were offered a $\$ 5$ honorarium or two bus tickets valued at $\$ 5.50$ for their time.

\section{Survey Development}

The research team met with staff members from the food bank to determine key areas of interest that would assist to address the organization's major knowledge gaps for service provision. Survey questions regarding socio-demographic characteristics, including gender, age, household size, education, and employment were adopted from validated questionnaires used in large national Canadian surveys ${ }^{17}$. When no previously used questions or tools of appropriate length could be found to address constructs of interest, additional questions were developed including questions related to household structure (age and sex of other household members, and 
relationship to participant), monthly household income range, household income sources, monthly housing cost range, food access points, adequacy of food obtained at the food bank, and change in hunger since first using the food bank. For household income ranges, cut-offs were used to reflect incomes below basic income assistance rates, and above measures commensurate with the Canadian "low-income cut-off"18. Dietary intake was assessed through food frequency questions adapted from the National Cancer Institute's Fruit and Vegetable Screener ${ }^{19}$.

The 18-item Household Food Security Survey Module (HFSSM) from the Canadian Community Health Survey was used to assess food insecurity status ${ }^{20}$. The module was developed through the process of identifying conditions and behaviour patterns that characterise a household's financial access to food. It recognizes that food insecurity is experienced on a spectrum, and as the number of affirmative responses to the survey questions increase, HFI categorization increases in severity. For this study, HFI categorization followed the method outlined by the PROOF research group in Canada, which recognizes four classifications of HFI: a) food secure, where households have adequate financial resources to access food; b) marginally food insecure, characterised by the psychosocial aspects of inadequate access to food, such as anxiety about running out of food; c) moderately food insecure, where households reduce quality of foods with potential reductions in quantity of food intake to make foods last; d) severely food insecure, which includes reductions in food quality and quantity, including skipping meals, experiencing hunger, losing weight, and/or potentially going for entire days without eating ${ }^{1}$.

Survey questions were further assessed by content experts $(n=6)$, food bank staff $(n=6)$, and a peer research assistant to evaluate content validity. The survey was also piloted with food bank staff and members $(n=19)$ to ensure appropriateness and clarity of questions and was delivered using the FluidSurveys ${ }^{\mathrm{TM}}$ web-based survey tool.

\section{Food bank organizational records}

Food bank usage data were collected retrospectively from an electronic system utilised by the food bank organization to monitor member access to their programs. Length of food bank use 
was determined from the date of initial sign up, and participants were coded as: "New users $<1$ year", "Medium term users 1-5 years", and "Long term users $\geq 5$ years". For frequency of use, date-of-access data were retrieved to characterize participants' food bank visits over the year prior to the study, to align with the time frame indicated in the HFSSM module ${ }^{20}$. Average frequencies of monthly visits over the past year were coded as "Low use $<1$ visit/month", "Medium use 1-2 visits/month", and "High use >2 visits/month".

\section{Data collection}

Trained interviewers administered an electronic survey with participants in a private space on-site at the food bank or over the phone. Interviewer administration of the survey was selected to build rapport between participants and the research team, improve response and completion rates, and to ensure that English reading level of participants would not affect results. Analysis

Frequencies and percentages were used to examine key variables of interest. Cross tabulations and Fisher's exact tests were used to examine associations between severe HFI and socio-demographic variables or food bank usage. Individuals reporting all other levels of food insecurity (secure, marginal, moderate) were combined into the reference category for Fisher's exact tests. The selection of Fisher's exact tests was due to the small sample size, the nonprobability sampling method, and non-equal distribution of variables resulting in small expected cell counts in contingency tables. An alpha level of 0.05 was selected to indicate statistical significance. All data were managed and analysed using STATA (StataCorp LP. Version 12.0, 2011).

\section{Results}

\section{Socio-demographic characteristics}

Of the 1085 unique members estimated to have accessed the three food bank sites during the recruitment period, 77 participants completed the survey. Gender was evenly distributed and 
the majority lived alone (58\%) and in adult-only households (90\%). Although $84 \%$ of participants were of government-recognized employment age ( $<65$ years old), only $19 \%$ reported employment. Most participants' households received social assistance (84\%), including income assistance/welfare (50\%) and/or disability benefits (61\%). Most participants reported very low incomes below $\$ 1200 /$ month (68\%), and the majority reported incomes $<\$ 1800 /$ month (91\%). Almost all participants (96\%) were renting their homes, and 45\% reported paying $>\$ 500$ in monthly rental costs. Most participants were long-term (>5 year) food bank members (54\%), and very few had used the food bank for less than one year (5.5\%). Participants accessed the food bank a mean of two times per month, and 55\% of participants were categorized as "high" frequency users (average use of $>2$ visits per month in the prior year) (Table 1).

Comparing sample characteristics with food bank organizational records of the larger member population, this sample closely reflected the gender divide and prevalence of singleperson households. However, the recruitment method did not effectively recruit larger family sizes, and there was a lower prevalence of short term $(<1$ year $)$ and low-frequency $(<1$ visit/month) users than organizational records indicated for the wider sampling frame.

Table 1 Food bank member sample characteristics

\begin{tabular}{|c|c|c|c|}
\hline Sample characteristics & & $\mathbf{n}$ & $\%$ \\
\hline \multirow[t]{2}{*}{ Gender $(n=76)$} & Male & 45 & 59 \\
\hline & Female & 31 & 41 \\
\hline \multirow[t]{3}{*}{ Household size $(n=77)$} & 1 & 45 & 58 \\
\hline & 2 & 15 & 20 \\
\hline & $\geq 3$ & 17 & 22 \\
\hline \multirow[t]{3}{*}{ Household structure $(n=77)$} & Adult only & 69 & 90 \\
\hline & 2 adult household $w /$ children $<18$ years & 6 & 8 \\
\hline & Single parent household & 2 & 3 \\
\hline \multirow[t]{2}{*}{ Education ( $n=76$ ) } & Less than secondary school diploma & 31 & 41 \\
\hline & Secondary school diploma or higher & 45 & 59 \\
\hline \multirow[t]{3}{*}{ Age $(n=76)$} & $18-39$ years & 13 & 17 \\
\hline & $40-64$ years & 51 & 67 \\
\hline & $\geq 65$ years & 12 & 16 \\
\hline \multirow[t]{2}{*}{ Employment $^{1}(n=77)$} & Yes & 15 & 19 \\
\hline & No & 62 & 81 \\
\hline
\end{tabular}


Table 1 Continued

\begin{tabular}{|c|c|c|c|}
\hline Sample characteristics & & $\mathbf{n}$ & $\%$ \\
\hline Household income sources ${ }^{2}$ & Income support - all types but pensions & 65 & 84 \\
\hline \multirow[t]{4}{*}{$(n=77)$} & Disability assistance & 47 & 61 \\
\hline & Wages & 22 & 29 \\
\hline & Government pensions (CPP, OAS, and GIS) & 19 & 25 \\
\hline & Other & 12 & 16 \\
\hline Household income, monthly & $\$ 0-599$ & 9 & 12 \\
\hline \multirow[t]{3}{*}{$(n=76)$} & $\$ 600-1199$ & 43 & 56 \\
\hline & $\$ 1200-1799$ & 17 & 22 \\
\hline & $\geq \$ 1800$ & 7 & 9 \\
\hline \multirow[t]{2}{*}{ Home ownership (n=77) } & Yes & 3 & 4 \\
\hline & No & 74 & 96 \\
\hline \multirow[t]{2}{*}{ Housing costs, monthly ( $n=77$ ) } & $\$ 0-500$ & 42 & 55 \\
\hline & $>\$ 500$ & 35 & 45 \\
\hline \multirow[t]{3}{*}{ Length of food bank use ${ }^{3}(n=74)$} & $<1$ Year & 4 & 5 \\
\hline & $1-5$ years & 30 & 41 \\
\hline & $>5$ years & 40 & 54 \\
\hline \multirow[t]{3}{*}{ Frequency of food bank use ${ }^{4}(n=67)$} & Low (<1 visits/month) & 11 & 16 \\
\hline & Medium (1-2 visits/month) & 19 & 28 \\
\hline & High (>2 visits/month) & 37 & 55 \\
\hline
\end{tabular}

Note: Total $n=77$. Sample size differed between variables due to missing values. Some totals not equal to $100 \%$ due to rounding.

1. Participant employment at time of survey

2. Household income sources, participants instructed to indicate all that apply

3. Calculated from participants' first recorded visit in the MMS database

4. Calculated from participants' average monthly visits over the past year as recorded in the MMS database

\section{Household food insecurity, food access, and dietary intake}

HFI was highly prevalent (97\%). Sixty-six percent of participants were categorized as severely food insecure, $30 \%$ were moderately food insecure, and $1 \%$ were marginally food insecure. Most participants (55\%) reported no change in hunger since first using the food bank, $36 \%$ reported reduced hunger, and $9 \%$ reported an increase. Sixty-two percent reported food bank provisions were not enough to meet their household need. When queried about other resources used to obtain food, $49 \%$ indicated free meal programs, $49 \%$ received food from family or friends, $26 \%$ grew food in gardens, and $14 \%$ used community kitchen programs. Twenty-five percent of participants consumed less than one serving of fruits or vegetables each day, and $80 \%$ 
consumed less than five servings per day. Eighty-two percent reported consuming animal-source protein less than once per day (Table 2).

Table 2 Experiences with household food insecurity and hunger

\begin{tabular}{|c|c|c|c|}
\hline \multicolumn{2}{|l|}{ Sample characteristics } & \multirow{2}{*}{$\frac{\mathrm{n}}{2}$} & \multirow{2}{*}{$\frac{\%}{3}$} \\
\hline Household food insecurity ${ }^{1}(n=74)$ & Food secure & & \\
\hline & Marginal food insecurity & 1 & 1 \\
\hline & Moderate food insecurity & 22 & 30 \\
\hline & Severe food insecurity & 49 & 66 \\
\hline \multirow[t]{3}{*}{ Change in hunger ${ }^{2}(n=77)$} & Decreased & 28 & 36 \\
\hline & Stayed about the same & 42 & 55 \\
\hline & Increased & 7 & 9 \\
\hline \multirow[t]{3}{*}{ Adequacy of food provisions ( $n=77$ ) } & Yes & 23 & 30 \\
\hline & Sometimes & 6 & 8 \\
\hline & No & 48 & 62 \\
\hline \multirow[t]{6}{*}{ Food access points ${ }^{3}(n=77)$} & Free meal programs & 37 & 49 \\
\hline & Friends & 37 & 49 \\
\hline & Not-for-profit grocery store & 24 & 31 \\
\hline & Garden & 19 & 26 \\
\hline & Low cost meal programs & 17 & 22 \\
\hline & Community kitchen programs & 10 & 14 \\
\hline \multirow[t]{3}{*}{ Fruit and vegetable intake, daily $(n=76)$} & $<1$ serving & 19 & 25 \\
\hline & $1-4.9$ servings & 42 & 55 \\
\hline & $\geq 5$ servings & 15 & 20 \\
\hline
\end{tabular}

Note: Total $n=77$. Sample size differed between variables due to missing values. Some totals not equal to $100 \%$ due to rounding

1. Household food insecurity category calculated using PROOF cut-off values for the HFSSM

Food secure $=0$ affirmative responses; Marginal Food Insecurity = 1 affirmative response; Moderate

Food Insecurity = 2-5 affirmative responses; Severe Food Insecurity $=6-10$

2. Participant reported change in hunger since first using the food bank

3. Food access points used in the past 30 days, participants instructed to indicate all that apply

4. As calculated from a FFQ, using number of times eaten in the past month and approximate portion sizes

\section{Associations between household food insecurity and sample characteristics}

Only two sample characteristics were found to be significantly associated with severe HFI: household incomes $<\$ 1800 /$ month $(\mathrm{p}=0.04)$, and monthly housing/rent costs of $>\$ 500$ $(p=0.01)$. When alternative categorizations of income (i.e. $\langle \$ 1200 /\rangle=\$ 1200)$ were tested, the association was no longer significant $(\mathrm{p}=0.30)$. No significant associations were found between 
severe HFI and length $(\mathrm{p}=0.30)$ or frequency of food bank use $(\mathrm{p}=0.94)$. No significant associations were found between severe HFI and reported change in hunger $(\mathrm{p}=0.61)$ or reported adequacy of food bank provisions $(\mathrm{p}=0.08)$.

Table 3 Associations between severe HFI and food bank member characteristics

\begin{tabular}{|c|c|c|c|c|}
\hline \multirow[t]{2}{*}{ Sample characteristics } & \multicolumn{2}{|c|}{ Severe HFI } & \multirow[t]{2}{*}{ Total } & \multirow[t]{2}{*}{ Fisher's exac } \\
\hline & No & Yes & & \\
\hline \multicolumn{5}{|l|}{ Gender } \\
\hline Male & $15(34 \%)$ & $29(66 \%)$ & 44 & \\
\hline Female & $10(33 \%)$ & $20(67 \%)$ & 30 & \\
\hline TOTAL & 25 & 49 & 74 & $p=1.00$ \\
\hline \multicolumn{5}{|l|}{ Age range } \\
\hline $18-64$ & $20(32 \%)$ & $42(68 \%)$ & 62 & \\
\hline$\geq 65$ & $5(42 \%)$ & 7 (58\%) & 12 & \\
\hline TOTAL & 25 & 49 & 74 & $p=0.53$ \\
\hline \multicolumn{5}{|l|}{ Household size } \\
\hline 1 & $14(33 \%)$ & $29(67 \%)$ & 43 & \\
\hline 2 & $6(40 \%)$ & $9(60 \%)$ & 15 & \\
\hline$\geq 3$ & 5 (31\%) & 11 (69\%) & 16 & \\
\hline TOTAL & 25 & 49 & 74 & $p=0.89$ \\
\hline \multicolumn{5}{|l|}{ Household structure } \\
\hline Adult-only & $23(35 \%)$ & $43(65 \%)$ & 66 & \\
\hline Children & $2(25 \%)$ & $6(75 \%)$ & 8 & \\
\hline TOTAL & 25 & 49 & 74 & $p=0.71$ \\
\hline \multicolumn{5}{|l|}{ Education } \\
\hline$<$ Secondary school & $13(43 \%)$ & $17(57 \%)$ & 30 & \\
\hline Secondary school & $7(23 \%)$ & $24(77 \%)$ & 31 & \\
\hline Completed post-secondary & $5(38 \%)$ & $8(62 \%)$ & 13 & \\
\hline TOTAL & 25 & 49 & 74 & $p=0.20$ \\
\hline \multicolumn{5}{|l|}{ Employment $^{1}$} \\
\hline Yes & $3(20 \%)$ & $12(80 \%)$ & 15 & \\
\hline No & $22(37 \%)$ & 37 (63\%) & 59 & \\
\hline TOTAL & 25 & 49 & 74 & $p=0.24$ \\
\hline \multicolumn{5}{|l|}{ Wages $^{2}$} \\
\hline Yes & 7 (32\%) & $15(68 \%)$ & 22 & \\
\hline No & $18(35 \%)$ & 34 (65\%) & 52 & \\
\hline TOTAL & 25 & 49 & 74 & $p=1.00$ \\
\hline \multicolumn{5}{|l|}{ Social assistance ${ }^{3}$} \\
\hline Yes & 21 (34\%) & $41(66 \%)$ & 62 & \\
\hline No & $4(33 \%)$ & $8(66 \%)$ & 12 & \\
\hline TOTAL & 25 & 49 & 74 & $p=1.00$ \\
\hline
\end{tabular}


Table 3 Continued

\begin{tabular}{|c|c|c|c|c|}
\hline \multirow[t]{2}{*}{ Sample characteristics } & \multicolumn{2}{|c|}{ Severe HFI } & \multirow[t]{2}{*}{ Total } & \multirow[t]{2}{*}{ Fisher's Exact } \\
\hline & No & Yes & & \\
\hline \multicolumn{5}{|l|}{ Disability benefits ${ }^{4}$} \\
\hline Yes & $17(39 \%)$ & $27(61 \%)$ & 44 & \\
\hline No & $7(24 \%)$ & $22(76 \%)$ & 29 & \\
\hline TOTAL & 25 & 49 & 74 & $p=0.12$ \\
\hline \multicolumn{5}{|c|}{ Government pensions $^{5}$ (CPP/ OAS/GIS) } \\
\hline Yes & $7(39 \%)$ & $11(61 \%)$ & 18 & \\
\hline No & $18(32 \%)$ & $38(68 \%)$ & 56 & \\
\hline TOTAL & 25 & 49 & 74 & $p=0.78$ \\
\hline \multicolumn{5}{|l|}{ Household income, monthly } \\
\hline$\$ 0-1799$ & $20(30 \%)$ & $46(70 \%)$ & 66 & \\
\hline$\geq \$ 1800$ & $5(71 \%)$ & $2(29 \%)$ & 7 & \\
\hline TOTAL & 25 & 48 & 73 & $p=0.04 *$ \\
\hline \multicolumn{5}{|l|}{ Housing costs, monthly } \\
\hline$\$ 0-500$ & $19(48 \%)$ & $21(53 \%)$ & 40 & \\
\hline$>\$ 500$ & $6(18 \%)$ & $28(82 \%)$ & 34 & \\
\hline TOTAL & 25 & 49 & 74 & $p=0.01^{*}$ \\
\hline \multicolumn{5}{|l|}{ Length of use } \\
\hline$<1$ Year & $0(0 \%)$ & $4(100 \%)$ & 4 & \\
\hline 1-5 years & $12(41 \%)$ & 17 (59\%) & 29 & \\
\hline$>5$ years & $12(32 \%)$ & $26(68 \%)$ & 38 & \\
\hline TOTAL & 24 & 47 & 71 & $p=0.30$ \\
\hline \multicolumn{5}{|l|}{ Frequency of use ${ }^{6}$} \\
\hline Low (<1 visits/month) & $3(30 \%)$ & $7(70 \%)$ & 10 & \\
\hline Medium (1-2 visits/month) & $6(32 \%)$ & $13(68 \%)$ & 19 & \\
\hline High (>2 visits/month) & $13(36 \%)$ & $23(64 \%)$ & 36 & \\
\hline TOTAL & 22 & 43 & 65 & $p=0.94$ \\
\hline $\begin{array}{l}\text { Note: Total } n=77 \text {. Sample size } d \\
\text { per row. Some totals not equal } \\
\text { 1. Participant employment at ti } \\
\text { 2. Wages received by any hous } \\
\text { 3. Social assistance (welfare an } \\
\text { 4. Disability benefits received b } \\
\text { 5. Government pension receive } \\
\text { 6. Average monthly visits over }\end{array}$ & $\begin{array}{l}\text { between } v \\
\% \text { due to ro } \\
\text { survey } \\
\text { nember } \\
\text { sability assi } \\
\text { household } n \\
\text { ny househo } \\
\text { t year }\end{array}$ & $\begin{array}{l}\text { bles due to } \\
\text { ling. }{ }^{*} p=< \\
\text { ce) receive } \\
\text { ber } \\
\text { eember }\end{array}$ & ng value & $\begin{array}{l}\text { tages calculated } \\
\text { ember }\end{array}$ \\
\hline
\end{tabular}

\section{Discussion}

These findings describe a high prevalence of incomes below the poverty line, unemployment, and receipt of government-based income support amongst this sample of 
Vancouver food bank members, consistent with other reports of food bank members' in Canada and the U.S. ${ }^{5,15}$. Ninety one percent of households sampled had monthly incomes below $\$ 1800$, (which approximates the low income cut-off (\$20,160/year) for single adults living in Vancouver ${ }^{18}$; reinforcing the economic vulnerability of these participants underlying their need for food bank services ${ }^{21}$. Although many participants could be considered working age, only $19 \%$ reported being employed, and most households received social assistance benefits as a source of income. An large number were currently receiving disability benefits, in a far higher proportion than the $19 \%$ of households reported in a recent national survey on food bank participation ${ }^{5}$. This finding is especially troubling given that receipt of disability benefits in Canada is due to recognized reliance on the government to assist in meeting basic needs stemming from issues that restrict an individual's ability to perform daily activities of living or maintain steady employment $^{22}$. Although disability benefits do provide more funds than basic income assistance, these social assistance rates have been continually found to be inadequate for ensuring financial access to basic living costs, including food ${ }^{1,5,23}$.

Single-person households represented $28.3 \%$ of BC households in the $2011 \mathrm{Census}^{24}$, but make up the largest proportion (42.9\%) of food insecure households ${ }^{6}$. This group represented $58 \%$ of our study sample, and coincides with national data from 2015 which reported that the prevalence of single-person households accessing food banks has grown since 2001, with the current prevalence in $\mathrm{BC}$ at $53.6 \%{ }^{5}$. The vulnerability of single-individual households is highlighted by their relatively high prevalence of food insecurity, which at $15.6 \%$ in Canada was second only to female lone-parent households ${ }^{1}$. Furthermore, income assistance rates for single adults under 65 have remained flat since $2008^{25}$. In the face of inadequate income assistance, and with less access to financial assistance and tax benefits brought from other household members (including partnerships and children), single individuals remain particularly vulnerable to inadequate financial resources and food insecurity ${ }^{25}$. 
Food banks were established to respond to emergency need, and although there has been little monitoring of individuals' length of use of these services, previous studies have noted that they are used as a long-term resource augmentation strategy by some members ${ }^{14,26}$. Most of the sample had been using services for greater than five years, and 55\% accessed services more than two times every month. These results are concerning as they reveal a frequency of use that could be described as 'regular' for many participants. This adds evidence to the critique of the term 'emergency assistance' to frame the services that food banks provide ${ }^{26}$, as it is not reflective of the experience of many individuals who use them. It is worth noting, that members with more frequent use may be overrepresented in this sample. Members who regularly visited the food bank during the weeks of study recruitment had more opportunities to interact with research staff, build rapport and had more opportunity to become engaged in this study.

Consistent with other recent Canadian studies ${ }^{13}$, severe HFI amongst our sample was highly prevalent. No demographic characteristics in this study were associated with severe HFI, but severe HFI was associated with two socio-economic indicators: household income, and housing costs. These findings come as no surprise, as HFI has been well reported to be associated with lower income in Canada given the financial underpinnings of the HFSSM ${ }^{1,27}$. However, significant associations with severe HFI were only found when incomes were dichotomized to those representing individuals above and below the low income cut-off ${ }^{18}$, and not when lower income cut-points were used. This may be reflective of the exceedingly low incomes that most participants reported, and the inability of incomes below the poverty level to protect against severe HFI. Recently, a Canadian study found that increasing income assistance rates can have a direct impact on HFI after finding that low-income seniors over age 65 experienced lower probability of food insecurity than younger (55-64 year old) low-income groups ${ }^{28}$. This is thought to be associated with the protective effects that come from a guaranteed income benefit, which provides a higher rate of social assistance for those 65 years of age or older. 
Severe HFI status did not differ significantly based on length or frequency of use. Similar results were found in a 1999 study from Toronto, where the frequency of food bank use of families with children was not correlated with HFI status ${ }^{14}$. These findings suggest that food banks do not appear to buffer the experiences of severe HFI for many users, even amongst those who use it frequently. Many participants described no subjective change in hunger since first using the food bank, and most reported that food bank provisions were not enough to meet their household needs. In addition to using the food bank, members were also accessing multiple resources to assist in meeting their food needs, and other studies from the US have determined that food bank members turn to multiple forms of food programs to obtain food ${ }^{29,30}$. Still, dietary intakes of fruits, vegetables, and protein rich foods were also described as low, consistent with national reports that food insecurity is associated with low fruit and vegetable intakes and low mean nutrient intakes of protein, vitamin B12, magnesium, zinc, and phosphorus ${ }^{10}$. Although food banks do offer needed food access, together these findings corroborate other studies documenting that food bank management and staff readily acknowledge that the food provided through these services are not sufficiently addressing members' food insecurity or dietary needs $\mathrm{s}^{31,32}$.

Strengths of our study included a rich set of survey questions developed with the input of a variety of community stakeholders. The interviewer-administered survey format also resulted in a low level of missing data. However, limitations of this study include the small, non-random, sampling method, constraining the generalizability of results. Future studies are needed to confirm these findings in larger, representative samples. Although our findings suggest that food bank use does not ameliorate severe HFI for this subsample of food bank members, food bank provisions may still offer some respite. This study did not collect repeated measures of HFI and cannot make any claims regarding the effectiveness of food bank use in reducing severity of food insecurity over time. Furthermore, as the HFSSM poses questions in relation to financial access, one could argue that assistance through charitable sources will not be reflected on a participant's 
categorization of HFI using this tool. Longitudinal evaluation of food bank usage patterns on HFI outcomes remains warranted. Additionally, qualitative studies are needed to better describe why food bank members elect to access food banks over the long-term or how food banks may buffer subjective experiences of hunger and food insecurity or contribute to other valuable outcomes such as social connectedness.

\section{Conclusion}

These results contribute to the understanding of the socio-demographic characteristics of food bank members in Vancouver. While most published Canadian studies on food bank use has focused on families with children, our findings are consistent with national Hunger Count reports that lone individual households are the most prevalent demographic amongst food bank members ${ }^{5}$ and are in need of more attention in research and food insecurity advocacy. Although not representative of all food bank members, our findings found extreme economic vulnerability and high prevalence of long-term regular reliance on food banks in this sample. Reports of unmet need and high prevalence of severe HFI amongst members add further weight to the argument that food banks are not a sufficient response to address HFI. Future public policy and research efforts should focus on poverty reduction and affordable housing, as they appear to be priority areas to reduce severe HFI amongst food bank members.

\section{References Cited}

1. Tarasuk V, Mitchell A, Dachner N. Household Food Insecurity in Canada, 2012. Toronto (ON): Research to identify policy options to reduce food insecurity (PROOF); 2014. http://proof.utoronto.ca/resources/proof-annual-reports/annual-report-2012. Accessed January $1,2014$.

2. Riches G, Tarasuk V. Canada: Thirty years of food charity and public policy neglect. In: First World Hunger Revisited: Food Charity or the Right to Food. 2nd ed. New York 
(NY): Palgrave Macmillan; 2014:42-56.

3. Tarasuk V, Dachner N, Loopstra R. Food banks, welfare, and food insecurity in Canada. Br Food J. 2014;116(9):1405-1417.

4. Riches G. Hunger in Canada: abandoning the right to food. In: Riches G, ed. First World Hunger: Food Security and Welfare Politics. Toronto (ON): University of Toronto Press; 1997.

5. Food Banks Canada. Hunger count 2015: a comprehensive report on hunger and food bank use in Canada. 2015:30. https://www.foodbankscanada.ca/Hunger-inCanada/Research.aspx. Accessed October 10, 2016.

6. Li N, Dachner N, Tarasuk V, et al. Priority Health Equity Indicators for British Columbia: Household Food Insecurity Indicator Report. Toronto (ON): Provincial Health Services Authority; 2016. http://proof.utoronto.ca/. Accessed September 2, 2016.

7. Loopstra R, Tarasuk V. The relationship between food banks and household food insecurity among low-income Toronto families. Can Public Policy. 2012;38(4):497-514.

8. Collins PA, Power EM, Little MH. Municipal-level responses to household food insecurity in Canada: a call for critical, evaluative research. Can J Public Health. 2014;105(2):138-141.

9. Tarasuk V, Beaton G. Women's dietary intakes in the context of household food insecurity. J Nutr. 1999;129(3):672-679.

10. Kirkpatrick S, Tarasuk V. Food insecurity is associated with nutrient inadequacies among Canadian adults and adolescents. J Nutr. 2008;138(1):604-612.

11. Tarasuk V, Cheng J, de Oliveira C, Dachner N, Gundersen C, Kurdyak P. Association between household food insecurity and annual health care costs. Can Med Assoc J. 2015;187(14):E429-36.

12. Tarasuk V, Mitchell A, McLaren L, McIntyre L. Chronic physical and mental health conditions among adults may increase vulnerability to household food insecurity. $J$ Nutr. 
2013;143(11):1785-1793.

13. Holben DH. Food bank users in and around the lower mainland of British Columbia, Canada are characterized by food insecurity and poor produce intake. J Hunger Environ Nutr. 2012;7(4):449-458.

14. Tarasuk V, Beaton G. Household food insecurity and hunger among families using food banks. Can J Public Health. 1999;90(2):109-113.

15. Robaina KA, Martin KS. Food insecurity, poor diet quality, and obesity among food pantry participants in Hartford, CT. J Nutr Educ Behav. 2013;45(2):159-164.

16. Minkler M, Wallerstein N, eds. Community-Based Participatory Research for Health: From Process to Outcomes. 2nd ed. San Francisco (CA): Jossey-Bass; 2011.

17. Statistics Canada. National Household Survey (NHS). Ottawa (ON): Statistics Canada; 2013. http://www23.statcan.gc.ca/imdb/p2SV.pl?Function=getSurvey\&SDDS=5178. Accessed February 16, 2015.

18. Statistics Canada. Low income cut-offs, after tax. 2016. http://www.statcan.gc.ca/pub/75f0002m/2015002/tbl/tb101-eng.htm. Accessed September 9, 2016.

19. National Cancer Institute. Fruit \& Vegetable Screeners in the Eating at America's Table Study (EATS): Overview. 2015. http://epi.grants.cancer.gov/diet/screeners/fruitveg/. Accessed June 5, 2016.

20. Bush M. Canadian Community Health Survey, Cycle 2.2, Nutrition (2004): Incomerelated household food security in Canada. 2007:108. http://www.hc-sc.gc.ca/fnan/surveill/nutrition/commun/income_food_sec-sec_alim-eng.php. Accessed November 1, 2016.

21. Statistics Canada. Income Research Paper Series. Ottawa (ON): Statistics Canada; 2015. http://www.statcan.gc.ca/pub/75f0002m/75f0002m2015002-eng.htm. Accessed June 5, 2016. 
22. Service Canada. Income assistance. Gov Canada. 2014.

http://www.servicecanada.gc.ca/eng/subjects/benefits//index.shtml. Accessed July 16, 2016.

23. Dietitians of Canada. Cost of eating in British Columbia 2011. 2012:16. http://www.dietitians.ca/Dietitians-Views/Food-Security/Household-Food-Insecurity/TheCost-of-Eating-in-British-Columbia.aspx. Accessed February 10, 2015.

24. Statistics Canada. Focus on Geography Series, 2011 Census: Province of British Columbia. Ottawa (ON): Statistics Canada; 2012. http://www12.statcan.gc.ca/censusrecensement/2011/as-sa/fogs-spg/Facts-pr-eng.cfm?Lang=Eng\&GC=59. Accessed July 30, 2016.

25. Stapleton J, Bednar V. Trading places: Single adults replace lone parents as the new face of social assistance in Canada. 2011:28. http://www.mowateitaskforce.ca/sites/default/files/Stapleton.pdf. Accessed September 7, 2016.

26. Starkey LJ, Kuhnlein H V, Gray-Donald K. Food bank users: sociodemographic and nutritional characteristics. Can Med Assoc J. 1998;158(9):1143-1149.

27. Che J, Chen J. Food insecurity in Canadian households. Health Reports. 2001;12(4):11-22 no. 82-003-X.

28. McIntyre L, Dutton DJ, Kwok C, Emery JCH. Reduction of food insecurity among lowincome Canadian seniors as a likely impact of a guaranteed annual income. Can Public Policy. 2016;42(3):274-286. doi:10.3138/cpp.2015-069.

29. Kicinski L. Characteristics of short and long-term food pantry users. Michigan Sociol Rev. 2012;26(1):58-74.

30. Weinfield NS, Mills WG, Institute U, et al. Hunger in America 2014: a report on charitable food distribution in the United States in 2013. 2014. http://www.feedingamerica.org/hunger-in-america/our-research/hunger-in-america/. 
Accessed October 5, 2016.

31. Tarasuk V, Eakin JM. Charitable food assistance as symbolic gesture: an ethnographic study of food banks in Ontario. Soc Sci Med. 2003;56(7):1505-1515.

32. Tarasuk V, Dachner N, Hamelin A-M, et al. A survey of food bank operations in five Canadian cities. BMC Public Health. 2014;14:1234. 